\title{
Peluang Riset Strategi Bumdes Sebagai Dasar Pengembangan Perekonomian Masyarakat: Sebuah Studi Literatur
}

\author{
M. Ihsan ${ }^{1}$, Irma $^{2}$, Burhanuddin Ladjin ${ }^{3}$, Arif Widyatama ${ }^{4}$ \\ ${ }^{1234}$ STIE Panca Bhakti, Palu, Indonesia

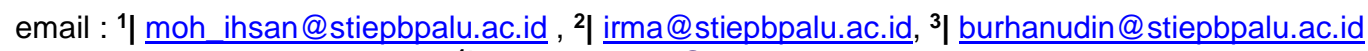 \\ ${ }^{4} \mid$ arifwidyatama@stiepbpalu.ac.id
}

\begin{abstract}
Abstrak
Tujuan artikel ini adalah untuk menemukan potensi riset mengenai strategi BUMDes Artikel ini dianggap penting karena penelitian mengenai BUMDes masih sangat terbatas sehingga dapat memberikan kontribusi yang sangat besar bagi ruang penelitian BUMDes. Bumdes memiliki peranan penting dalam membangun perekonomian di desa. Namun kondisi yang terjadi adalah masih banyak kondisi dari SDM masyarakat desa terutama pengurus Bumdes masih belum memiliki kemampuan manajemen dan literasi keuangan yang baik dalam mengurus Bumdes. Penelitian ini dilakukan dengan studi literature dengan menggunakan Leximancer untuk menentukan potensi riset kedepannya. Hasil penelitian ini menunjukkan bahwa terdapat 4 (empat) variabel penting yang perlu diperhatikan oleh penelitian selanjutnya yaitu environmental, business, innovation dan performance.
\end{abstract}

Kata Kunci : Strategi BUMDes, Innovation, Enviromental, Studi literatur

\begin{abstract}
The purpose of this article is to discover the potential for research on BUMDes strategies. This article is considered important because research on BUMDes is still very limited so that it can make a very large contribution to BUMDes research space. Bumdes has an important role in building the economy in the village. However, the condition that occurs is that there are still many conditions of rural community human resources, especially Bumdes officials, who do not have good management skills and financial literacy in managing Bumdes. This research was conducted with a literature study using Leximancer to determine the potential for future research. The results of this study indicate that there are 4 (four) important variables that need to be considered by further research, namely environmental, business, innovation and performance.
\end{abstract}

Keywords: BUMDes Strategy, Innovation, Environmental, Literature study

\section{Pendahuluan}

Badan Usaha Milik Desa merupakan sebuah organisasi yang bertujuan untuk meningkatkan perekonomian masyarakat desa. Tujuan utama adalah agar dapat membangun sebuah desa mandiri. Posisi BUMDes menjadi lembaga yang memunculkan sentra-sentra ekonomi di desa dengan semangat ekonomi kolektif. Dalam rangka meningkatkan pendapatan masyarakat dan pendapatan asli desa maka BUMDes ini mempunyai beberapa kontribusi untuk memenuhi kebutuhan masyarakat, salah satunya dlam kebutuhan pokok di desa. Mengingat BUMDes ini adalah suatu lembaga ekonomi modal usaha, BUMDes ini ialah sebagai salah satu pembangunan desa mandiri yang dapat berjalan dengan percaya diri bahwa desa memang sudah berhasil mengatur rumah tangganya sendiri dan menciptakan desa yang mandiri

Namun beberapa penelitian sebelumnya masih sedikit yang membahas mengenai Bumdes (Baldo, 2012; Kurniasih et al., 2019; U \& Majid AH, 2015; Whiteley \& Kölln, 2018; 
Widyatama \& Yanida, 2016). Penelitian tersebut masih berfokus pada pengembangan UMKM namun tidak berfokus pada pengembangan strategi Bumdes. Sehingga hal ini menjadi potensi besar serta memberikan kontribusi yang besar pada pengembangan Bumdes mengingat penelitian mengenai Bumdes masih jarang dilakukan (Adomako et al., 2016; Desiyanti, 2016; Eniola \& Entebang, 2017; Fujiki, 2020; Lambregts \& Schut, 2020; Ma'ruf, 2019; Mabula \& Ping, 2018a; Widayanti et al., 2017).

Bumdes memiliki peranan penting dalam membangun perekonomian di desa. Namun kondisi yang terjadi adalah masih banyak kondisi dari SDM masyarakat desa terutama pengurus Bumdes masih belum memiliki kemampuan manajemen dan literasi keuangan yang baik dalam mengurus Bumdes .(Anggraeni, 2016; Hussain, Salia and Karim, 2018; Nohong et al., 2019; Herawati et al., 2020). Keberadaan Bumdes dapat memberikan dampak positif bagi masyarakat jika Bumdes tersebut memiliki kemampuan untuk mengelola dananya sehingga memiliki manfaat bagi masyarakat. Keberadaan BUMDes ini dalam mengembangkan perekonomian masyarakat Desa maka diperlukan strategi yang tepat untuk digunakan sehingga dapat memberikan dampak yang signifikan bagi pengembangan masyarakat Desa.

Strategi yang sesuai sangat penting untuk dimiliki dan dilakukan oleh setiap pengurus Bumdes. Strategi yang dibutuhkan oleh setiap pengurus Bumdes akan berbeda-beda tergantung dari masalah yang dihadapi oleh setiap pengurus (Mabula \& Ping, 2018b; Novi Yushita Amanita, 2017; Owusu et al., 2019; Sugiarti et al., 2019). Kondisi ini akan bermacam-macam mengingat banyaknya perbedaan masalah yang dihadapi oleh setiap pengurus Bumdes dalam Bumdesnya (Agyei et al., 2019; Djuwita \& Yusuf, 2018; Ye \& Kulathunga, 2019). Banyak hal yang mempengaruhi strategi sebuah perusahaan dalam menjalankan bisnis terutama Bumdes. Strategi yang dilaksanakan oleh setiap pengurus BUMDes akan disesuaikan dengan kondisi setiap BUMDes. Oleh sebab itu pembahasan mengenai strategi BUMDes dalam pengembangan perekonomian masyarakat Desa masih perlu dibahas lebih lanjut.

Penelitian ini bertujuan untuk memberikan penekanan mengenai pentingnya strategi yang dapat digunakan oleh masing-masing pengurus BUMDes dalam proses pengembangan perekonomian masyarakat sehingga nantinya memberikan kontribusi kepada pengurus BUMDes agar dapat dijadikan acuan bagi pengurus BUMDes. Penelitian ini juga memberikan tujuan mengenai peluang riset yang dapat dikembangkan untuk penelitian selanjutnya.

Artikel ini memiliki kontribusi mengenai potensi riset di masa depan mengenai strategi yang dapat dikembangkan oleh BUMDes. Kontribusinya bagi penelitan selanjutnya dapat melihat peluang riset yang dapat dilakukan oleh BUMDes.

\section{Metode}

Artikel ini menggunakan studi literatur dengan memeriksa dan mengidentifikasi secara komprehensif artikel yang berhubungan dengan strategi yang dilakukan oleh BUMDes. Studi ini akan menjadi langkah untuk memetakan hubungan antara strategi dalam pengemangan perekonomian masyarakat Desa. Pada proses pemetaan ini akan menggunakan program leximancer dalam membuat peta hubungan antara variabel. Proses pencarian data ini dilakukan dengan melakukan pencarian pada database https://www.sciencedirect.com/ dengan menggunakan kata kunci "SME's" AND "Strategy" sehingga diperoleh artikel sejumlah 25 artikel sebagai dasar untuk melihat peta penelitian dari sumber paper rujukan tersebut. Selanjutnya 25 paper yang telah dikumpulkan tersebut akan diolah menggunakan dengan aplikasi leximancer untuk melihat strategy yang digunakan oleh BUMDes. Penelitian ini menggunakan kata kunci "SME's" karena secara struktur perusahaan SME's hampir sama dengan BUMDes hanya perbedaan pada pelaksanaan lokasi dan sumber alokasi modal yang sepenuhnya berada di Desa. Penelitian ini tidak menggunakan kata kunci "BUMDes" atau " village-owned enterprises" karena penelitian mengenai BUMDes yang dipublikasi pada jurnal bereputasi masih sangat terbatas. Artikel yang digunakan merupakan artikel selama 5 tahun terakhir yaiut dari tahun 2015 hingga 2020. Tinjauan pustaka ini menggunakan berbagai sumber yang terkait dengan penggunaan strategi dalam BUMDes 
dalam proses pengembangan perekonomian masyarakat. Studi literatur ini dapat digunakan untuk mengidentifikasi penyebab perundingan yang telah dilakukan oleh pengurus BUMDes dan nantinya dapat menjadi acuan bagi riset kedepannya dalam menentukan arah riset mengenai BUMDes.

\section{Hasil dan Pembahasan}

Berdasarkan hasil analisis maka artikel yang digunakan oleh penelitian sebanyak 25 sebagai berikut:

\begin{tabular}{lll}
\hline No. & \multicolumn{1}{c}{ Nama Author } & \multicolumn{1}{c}{ Nama Jurnal } \\
\hline 1 & (Lorentz et al., 2016) & Expert Systems With Applications \\
2 & (Santoro et al., 2019) & Journal of Business Research journal \\
3 & (Cariola et al., 2020) & Journal of Cleaner Production journal \\
4 & (De Marco et al., 2020) & Technological Forecasting \& Social Change \\
5 & (Florido et al., 2015) & Procedia - Social and Behavioral Sciences 174 \\
6 & (Cosenz \& Bivona, 2020) & Journal of Business Research journal \\
7 & (Ejdys, 2014) & Procedia - Social and Behavioral Sciences \\
8 & (Omri et al., 2020) & Journal of Manufacturing Systems jo \\
9 & (Gunjati \& Adake, 2020) & Materials Today: Proceedings journal \\
10 & (Eggers, 2020) & Journal of Business Research journal \\
11 & (Lu et al., 2020) & Journal of Cleaner Production journal \\
12 & (Hossain et al., 2020) & Economic Modelling journal \\
13 & (Westman et al., 2020) & Earth System Governance journal \\
14 & (Gancarczyk \& Gancarczyk, & European Management Journal journal \\
& 2018) & \\
15 & (Bhamra et al., 2018) & The Journal of Design, Economics, and \\
& & Innovation \\
16 & (Paul, 2020) & European Management Journal journal \\
17 & (van Rijnsoever et al., 2017) & Technological Forecasting \& Social Change \\
& & Seduced \\
18 & (Ausloos et al., 2018) & Physica A \\
19 & (Benhayoun et al., 2020) & Technological Forecasting \& Social Change \\
20 & (Nisar et al., 2018) & Research in International Business and Finance \\
21 & (Chege \& Wang, 2020) & Journal of Rural Studies journal \\
22 & (Müller et al., 2020) & European Management Journal \\
23 & (Woodard, 2020) & Journal of Cleaner Production journal \\
24 & (Kottika et al., 2020) & Industrial Marketing Management \\
25 & (Knight et al., 2020) & International Business Review journal \\
\hline & &
\end{tabular}

Peneliti telah melakukan pencarian pada 25 artikel tersebut yang memiliki kaitan antara strategy dan UMKM. UMKM yang dimaksud disini sama dengan Badan Usaha Milik Desa sehingga strategy yang digunakan untuk meningkatkan kinerja dari BUMDes sama dengan UMKM. Selanjutnya dari 25 jurnal tersebut dilakukan pengolahan menggunakan aplikasi leximancer untuk melihat hubungan dari masing-masing paper tersebut yang memiliki kaitan dengan Strategy yang digunakan oleh BUMDes yang dapat diterapkan dalama pengembangan Desa.

\section{Komposisi peluang riset masa depan dengan topic BUMDes}

Pada sub bab ini akan membahas mengenai peluang riset yang dapat dilakukan oleh peneliti selanjutnya gunakan untuk membahas riset mengenai BUMDes agar nantinya kedepannya peneliti selanjutnya dapat menggunakan dasar ini sebagai acuan memulai penelitian mengenai BUMDes. Penelitian ini dalam menentukan peluang riset masa depan mengenai BUMDes menggunakan aplikasi Leximancer untuk menentukan variable-variabel yang mempengaruhi strategi pengembangan BUMDes dengan menggunakan 25 artikel tersebut. 
Berdasarkan hasil pengolahan dengan menggunakan aplikasi leximance maka diperoleh sebuah gambar yang menunjukkan keterkaitan antara variable sebagai berikut

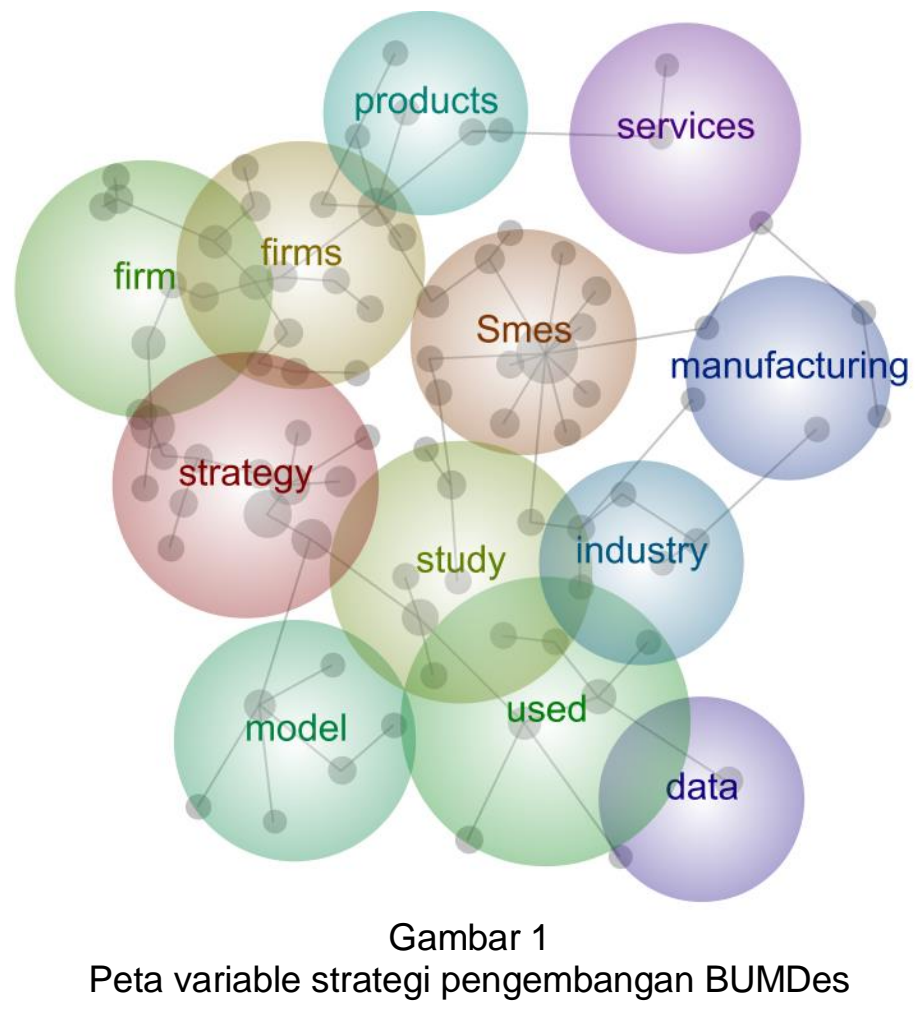

Pada gambar 1 di atas maka dapat diuraikan bahwa terdapat model yang dapat digunakan atau dibuat untuk dapat menentukan model yang tepat dan menjadi trend riset di masa depan. Terlihat pada gambar 1 tersebut strategy yang digunakan oleh BUMDes berlaku pada berbagai industry yaitu baik industry manufaktur ataupun jasa. Sehingga strategy yang digunakan nantinya dapat secara menyeluruh dilakukan pada seluruh BUMDes (Cheng \& Schwienbacher, 2016; Liu \& Wong, 2018; Ruan \& Zhang, 2014; Wiemer, 1994; Zhang, 2019; Zhao \& Zhang, 2018).

Gambar 1 tersebut menunjukkan mengenai beberapa peta hubungan variable dalam pengembangan BUMDes. Pada gambaer tersebut menunjukkan bahwa bagi pengembangan BUMDes kedepannya masih berfokus pada pengembangan industry manufaktur. Industri manufaktur masih menjadi sentra poin bagi BUMDes dalam hal ini manajer/pengelola BUMDes untuk dapat focus pada unit bisnisnya. Sehingga strategi yang dimiliki oleh manajer/ketua BUMDes menjadi core of the core dalam pengembangan bisnis. Strategi yang sesuai sangat penting untuk dimiliki dan dilakukan oleh setiap pengurus Bumdes. Strategi yang dibutuhkan oleh setiap pengurus Bumdes akan berbeda-beda tergantung dari masalah yang dihadapi oleh setiap pengurus (Mabula \& Ping, 2018b; Novi Yushita Amanita, 2017; Owusu et al., 2019; Sugiarti et al., 2019). Kondisi ini akan bermacam-macam mengingat banyaknya perbedaan masalah yang dihadapi oleh setiap pengurus Bumdes dalam Bumdesnya (Agyei et al., 2019; Djuwita \& Yusuf, 2018; Ye \& Kulathunga, 2019). Banyak hal yang mempengaruhi strategi sebuah perusahaan dalam menjalankan bisnis terutama Bumdes. Strategi yang dilaksanakan oleh setiap pengurus BUMDes akan disesuaikan dengan kondisi setiap BUMDes.

Poin kedua yang penting untuk diperhatikan dalam pengembangan bisnis adalah unit bisnis yang perlu diperhatikan oleh manajer BUMDes adalah service atau berhubungan dengan jasa. Hal tersebut terlihat pada point pemetaan pada gambar 1 tersebut. Selain focus pada industry manufaktur, pengelola BUMDes juga harus focus pada jasa seperti simpan pinjam atau pariwisata. Namun yang perlu diperhatikan adalah dalam pengembangan BUMDes adalah keunikan serta keunggulan dari sebuah daerah yang 
berada di lokasi BUMDes. Hal ini perlu dipertimbangkan agar menjadi komiditi serta keunggulan dari BUMDes tersebut.

Badan Usaha Milik Desa merupakan sebuah organisasi yang bertujuan untuk meningkatkan perekonomian masyarakat desa. Tujuan utama adalah agar dapat membangun sebuah desa mandiri. Posisi BUMDes menjadi lembaga yang memunculkan sentra-sentra ekonomi di desa dengan semangat ekonomi kolektif. Dalam rangka meningkatkan pendapatan masyarakat dan pendapatan asli desa maka BUMDes ini mempunyai beberapa kontribusi untuk memenuhi kebutuhan masyarakat, salah satunya dlam kebutuhan pokok di desa. Mengingat BUMDes ini adalah suatu lembaga ekonomi modal usaha, BUMDes ini ialah sebagai salah satu pembangunan desa mandiri yang dapat berjalan dengan percaya diri bahwa desa memang sudah berhasil mengatur rumah tangganya sendiri dan menciptakan desa yang mandiri .

Namun beberapa penelitian sebelumnya masih sedikit yang membahas mengenai Bumdes (Baldo, 2012; Kurniasih et al., 2019; U \& Majid AH, 2015; Whiteley \& Kölln, 2018; Widyatama \& Yanida, 2016). Penelitian tersebut masih berfokus pada pengembangan UMKM namun tidak berfokus pada pengembangan strategi Bumdes. Sehingga hal ini menjadi potensi besar serta memberikan kontribusi yang besar pada pengembangan Bumdes mengingat penelitian mengenai Bumdes masih jarang dilakukan (Adomako et al., 2016; Desiyanti, 2016; Eniola \& Entebang, 2017; Fujiki, 2020; Lambregts \& Schut, 2020; Ma'ruf, 2019; Mabula \& Ping, 2018a; Widayanti et al., 2017). Sekolah Tinggi Ilmu Ekonomi (STIE) Panca Bhakti Palu dalam menyelenggarakan Tri Dharma Perguruan Tinggi, sejak tahun 2017 telah berkomitmen untuk ikut serta dalam membangun desa dengan mendampingi beberapa desa yang membutuhkan pembinaan dan pengembangan sumberdaya aparat desa dan BUMDes. Saat ini ada 16 Desa yang menjadi binaan STIE Panca Bhakti Palu yang tersebar di Kabupaten Sigi dan Kabupaten Poso. Sesuai data dari Badan Pemberdayaan Masyarakat dan Desa Provinsi Sulawesi Tengah terdapat 14 BUMDes di wilayah desa binaan tersebut.

Pada penelitian ini menggunakan Resource based view (RBV) untuk menjelaskan mengenai kemampuan perusahaan untuk menggunakan sumber-sumber daya internalnya untuk mengembangkan usahanya. Menurut Barney (1991) penting bagi perusahaan untuk mengetahui sumber-sumber daya internalnya agar perusahaan dapat membuat berbagai macam strategi yang terkait kemampuan perusahaannya. Sehingga RBV menolak teori industrial organization yang lebih cenderung fokus pada pihak eksternal yang memengaruhi strategi perusahaan. RBV menganggap bahwa ketika perusahaan fokus untuk mengembangkan sumber-sumber daya internalnya dan mampu memaksimalkan sumber daya tersebut maka hal tersebut dapat menjadikan keunggulan perusahaan tidak hanya pada bentuk strategi yang berbeda namun juga pada peningkatkan kinerja perusahaan yang dimiliki oleh perusahaan. RBV dijadikan sebagai salah satu konsep dasar untuk menjelaskan hubungan antara pemetaan variable dari model penelitian ini.

Pada gambar 2 menunjukkan peta konsep mengenai strategi pengembangan BUMDes. Hasil konsep itu diperoleh dari aplikasi leximancer dengan melakukan pengumpulan data pada 25 jurnal yang telah disebutkan diatas. Berbeda pada gambar 1 , pada gambar 2 lebih cenderung terlihat konsep-konsep yang dapat menjadi bentuk pengembangan untuk bias menghubungkan variable-variabelnya.

Pada gambar dua lebih spesifik lebih menentukan konsep yang dapat digunakan mengenai tema yang dapat digunakan. Pada tema strategi kita bias menentukan bahwa terhadap konsep-konsep yang perlu diperhatikan dalam pengembangan strategi BUMdes, seperti konsep 'enviromental', innovation, dan organizational performance. Hal ini menjadi penting dan sesuai dengan peta riset pada masa kini dan masa depan bahwa ketiga hal tersebut menjadi isu yang sangat penting dalam pengembangan strategi BUMDes. Mengacu pada konsep SDGs bahwa pada 30 tahun kedepan hal atau isu yang menjadi focus dari dunia adalah isu mengenai lingkungan. Hal ini sesuai dengan kondisi saat ini yang menjelaskan bahwa hal yang menjadi focus adalah mengenai lingkungan. Oleh sebab itu berdasarkan kondisi ini perlu untuk membuat atau mengkaji lebih mendalam mengenai isu lingkungan dengan strategi BUMDes. BUMDes tidak lagi hanya focus pada bisnis yang 
bersifat rutinitias namun juga penting agar focus pada masalah lingkungan sehingga komoditi dari lingkungan BUMDes perlu ditingkatkan sehingga dapat menjadi komoditi unggulan.

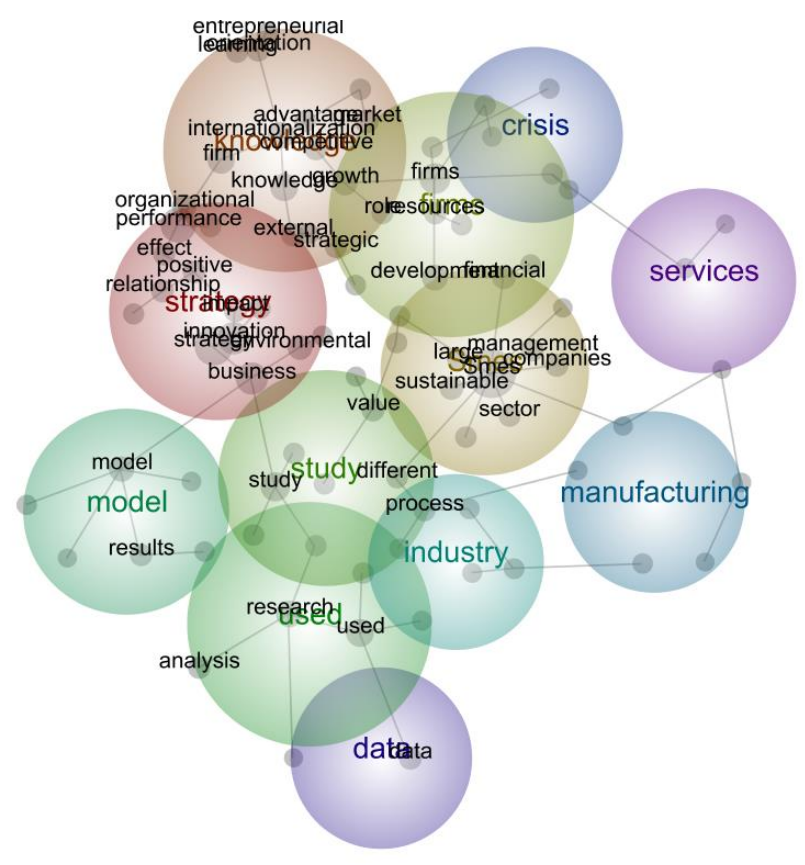

Gambar 2

Peta konsep strategi pengembangan BUMDes

Namun dalam mengembangkan komoditi unggulan tersebut diperlukan inovasi dari pengurus BUMDes. Untuk mengembangkan sebuah perusahaan agar berinovasi atau meningkatkan kinerja perusahaan tidak hanya dengan pemupukan modal, tapi perlu juga pemanfaatan sumber daya manusia yang berada di internal. Ketika suatu perusahaan memiliki sumber daya internal yang memumpuni dalam secara langsung hal tersebut dapat membuat perusahaan tersebut akan selalu berinovasi. Ketika perusahaan selalu berinovasi maka hal tersebut dapat meningkatkan kinerja perusahaannya. Hal ini sejalan dengan penelitian yang dilakukan oleh (Abdul-Halim et al. 2019; Agostini, L., \& Nosella 2017; Dabić et al. 2018; Gonzalez-Loureiro, Sousa, and Pinto 2017; Hult, Hurley, and Knight 2004; Jansen, Van Den Bosch, and Volberda 2006; Kianto, Sáenz, and Aramburu 2017; Montequín et al. 2006; Ramadan et al. 2017; Rodrigues, Dorrego, and Jardon 2011).

Selanjutnya yang menjadi hal yang penting adalah masalah value. Masalah value ini adalah hal yang sangat penting untuk membedakan keunggulan BUMDes dengan BUMDes yang lain. Pada dewasa ini BUMDes masih fokus ada kegiatan yang bersifat rutinitas sehingga diperlukan sebuah inovasi yang dapat menciptakan nilai bagi BUMDes tersebut agar dapat membedakan BUMDes tersebut dengan BUMDes lainnya. Berikut merupakan hasil pemetaan untuk potensi riset di masa depan mengenai BUMDes.

Pada gambar 3 ini dapat dijelaskan peta penelitian serta variable yang dapat dijadikan referensi bagi penelitian selanjutnya untuk dapat melakukan riset mengenai BUMDes. Variable innovation dan environmental, Bussiness serta Performance menjadi variable-variabel yang dapat dijadikan dasar untuk dapat melakukan riset mengenai BUMDes ketika dikaitkan dengan strategi. Variabel enviromental menjadi salah satu isu yang sangat penting dikarenakan di Indonesia sudah tergabung dan fokus pada SDGs hingga 30 tahun, sehingga ketika penelitian BUMDes dikaitkan dengan enviromental maka dapat menjadi peluang riset yang besar. Selain itu faktor innovation menjadi hal yang penting bagi BUMDes, karena BUMDes yang membuat stagnan adalah tidak adanya innovation yang dilakukan oleh BUMDes sehingga dari hasil penelitian ini membuat dianggapnya perlu untuk memerhatikan variabel innovation. 


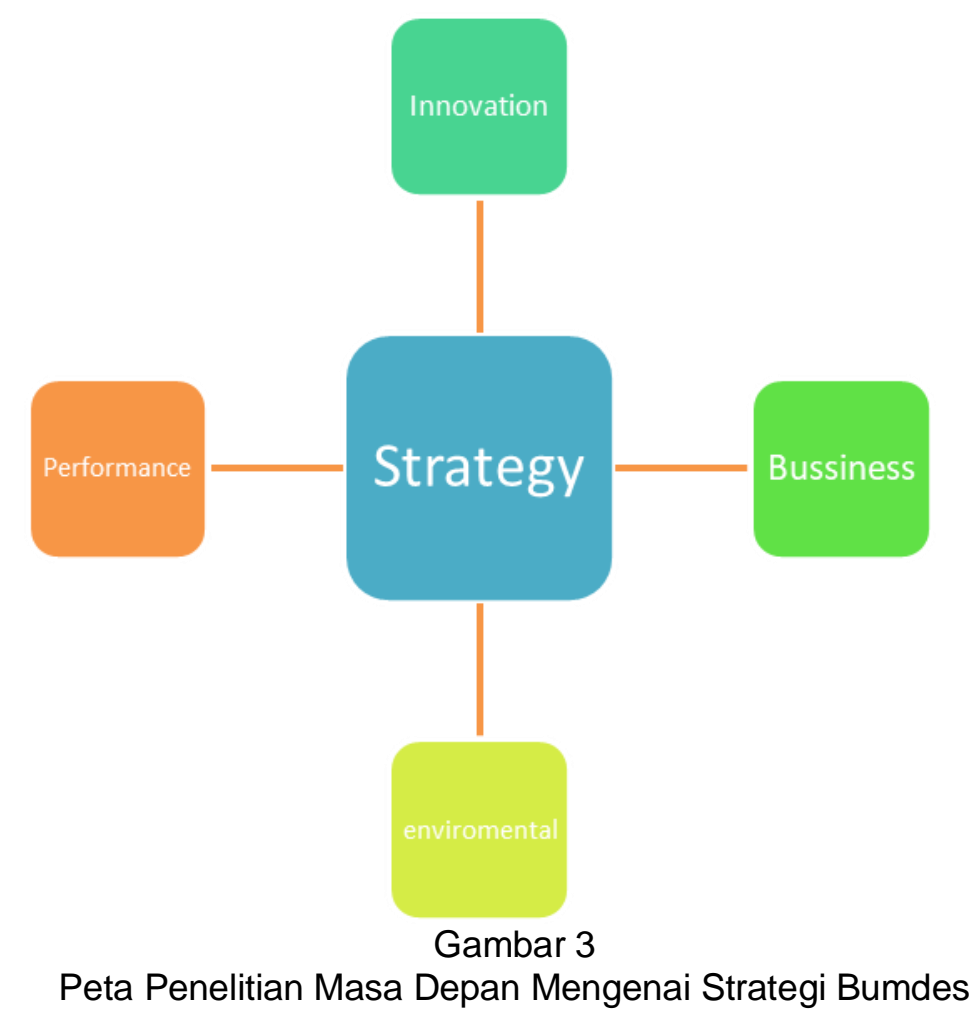

\section{Simpulan Dan Saran}

Berdasarkan dari pembahasan di atas maka dapat disimpulkan bahwa terdapat beberapa konsep yang dapat dijadikan acuan untuk penelitian masa depan mengenai BUMDes yaitu adalah masalah enviromental, dan Innovation. Kedua hal tersebut menjadi dua unsur penting dalam menjadi peluang riset masa depan serta perhatian BUMDes di masa depan. Isu lingkungan menjadi hal yang sangat krusial saat ini terutama permasalahan lingkungan juga menjadi hal penting dalam dan isu yang penting dalam SDGs. Sedangkan innovation juga menjadi hal yang paling mendasar dalam BUMDes. Hal ini dikarenakan innovation menjadi hal yang sangat diperlukan untuk dapat membuat BUMDes bisa lebih berkembang terutama ketika harus bersaing dengan perusahaanperusahaan besar.Penelitian ini memiliki keterbatasan yaitu dalam penentuan database hanya mengacu pada www.sciendirect.com tidak pada database yang lain. Selanjutnya artikel yang diperoleh hanya secara subjektif diambil oleh peneliti berdasarkan pencarian yang paling relevan sehingga ada kemungkinan jika menggunakan artikel lain akan menimbulkan hasil yang berbeda.

\section{Ucapan Terima Kasih}

Terima kasih kepada Direktorat Riset dan Pengabdian Masyarakat, Direktorat Jenderal Penguatan Riset dan Pengembangan Kementerian Riset, teknologi, dan Pendidikan Tinggi Republik Indonesia. Penelitian ini didanai oleh Direktorat Riset dan Pengabdian Deputi Bidang Penguatan Riset dan Pengembangan Kementeriaan Riset dan Teknologi/Badan Riset dan Inovasi Nasional sesuai dengan Kontrak Pelaksanaan Program Pengabdian kepada Masyarakat Nomor SK Penerimaan Pendanaan Penelitian dan Pengabdian kepada Masyarakat B/87/E3/RA.00/2020 tanggal 28 Januari 2020, dan Kontrak Pelaksanaan Program Pengabdian kepada Masyarakat Tahun Anggaran 2020 Nomor 2851/LL9/AM/2020

\section{Daftar Pustaka}

Adomako, S., Danso, A., \& Ofori Damoah, J. (2016). The moderating influence of financial literacy on the relationship between access to finance and firm growth in Ghana. 
Venture Capital, 18(1), 43-61. https://doi.org/10.1080/13691066.2015.1079952

Agyei, S. K., Adam, A. M., \& Agyemang, O. S. (2019). Financial Literacy, Cultural Dominance, and Financial Well-Being of SME Owners in Ghana. Poverty and Public Policy, 11(3), 222-237. https://doi.org/10.1002/pop4.254

Anggraeni, B. D. (2016). Pengaruh Tingkat Literasi Keuangan Pemilik Usaha Terhadap Pengeloaan Keuangan. Studi Kasus: Umkm Depok. Jurnal Vokasi Indonesia, 4(1). https://doi.org/10.7454/jvi.v4i1.50

Ausloos, M., Cerqueti, R., Bartolacci, F., \& Castellano, N. G. (2018). SME investment best strategies. Outliers for assessing how to optimize performance. Physica A: Statistical $\begin{array}{llll}\text { Mechanics and Its } & \text { 75plications, }\end{array}$ https://doi.org/10.1016/j.physa.2018.06.039

Baldo, M. Del. (2012). Corporate social responsibility and corporate governance in Italian SMEs: The experience of some "spirited businesses." In Journal of Management and Governance (Vol. 16, Issue 1). https://doi.org/10.1007/s10997-009-9127-4

Benhayoun, L., Le Dain, M. A., Dominguez-Péry, C., \& Lyons, A. C. (2020). SMEs embedded in collaborative innovation networks: How to measure their absorptive capacity? Technological Forecasting and Social Change, 159(June), 120196. https://doi.org/10.1016/j.techfore.2020.120196

Bhamra, T., Hernandez, R. J., Rapitsenyane, Y., \& Trimingham, R. (2018). Product Service Systems: A Sustainable Design Strategy for SMEs in the Textiles and Leather Sectors. She Ji, 4(3), 229-248. https://doi.org/10.1016/j.sheji.2018.07.001

Cariola, A., Fasano, F., La Rocca, M., \& Skatova, E. (2020). Environmental sustainability policies and the value of debt in EU SMEs: Empirical evidence from the energy sector. Journal of Cleaner Production, 275. https://doi.org/10.1016/j.jclepro.2020.123133

Chege, S. M., \& Wang, D. (2020). The impact of entrepreneurs' environmental analysis strategy on organizational performance. Journal of Rural Studies, 77(April 2019), 113125. https://doi.org/10.1016/j.jrurstud.2020.04.008

Cheng, C., \& Schwienbacher, A. (2016). Venture capital investors and foreign listing choices of Chinese companies. Emerging Markets Review, 29, 42-67. https://doi.org/10.1016/j.ememar.2016.08.007

Cosenz, F., \& Bivona, E. (2020). Fostering growth patterns of SMEs through business model innovation. A tailored dynamic business modelling approach. Journal of Business Research, February, 1-12. https://doi.org/10.1016/j.jbusres.2020.03.003

De Marco, C. E., Martelli, I., \& Di Minin, A. (2020). European SMEs' engagement in open innovation When the important thing is to win and not just to participate, what should innovation policy do? Technological Forecasting and Social Change, 152(December 2019), 119843. https://doi.org/10.1016/j.techfore.2019.119843

Desiyanti, R. (2016). Literasi dan Inklusi Keuangan serta Indeks Utilitas UMKM di Padang. BISMAN Jurnal Bisnis \& Manajemen, 2(2), 122-134.

Djuwita, D., \& Yusuf, A. A. (2018). Tingkat Literasi Keuangan Syariah Di Kalangan UMKM Dan Dampaknya Terhadap Perkembangan Usaha. Al-Amwal: Jurnal Ekonomi Dan Perbankan Syari'ah, 10(1), 105. https://doi.org/10.24235/amwal.v10i1.2837

Eggers, F. (2020). Masters of disasters? Challenges and opportunities for SMEs in times of crisis. Journal of Business Research, 116(May), 199-208. https://doi.org/10.1016/j.jbusres.2020.05.025

Ejdys, J. (2014). Future Oriented Strategy for SMEs. Procedia - Social and Behavioral Sciences, 156(April), 8-12. https://doi.org/10.1016/j.sbspro.2014.11.110 
Eniola, A. A., \& Entebang, H. (2017). SME Managers and Financial Literacy. Global Business Review, 18(3), 559-576. https://doi.org/10.1177/0972150917692063

Florido, J. S. V., Adame, M. G., \& Tagle, M. A. O. (2015). Financial Strategies, the Professional Development of Employers and Performance of sme's (AGUASCALIENTES Case). Procedia - Social and Behavioral Sciences, 174, 768-775. https://doi.org/10.1016/j.sbspro.2015.01.613

Fujiki, H. (2020). Cash demand and financial literacy: A case study using Japanese survey data. Japan and the World Economy, 54(February 2019), 100998. https://doi.org/10.1016/j.japwor.2020.100998

Gancarczyk, M., \& Gancarczyk, J. (2018). Proactive international strategies of cluster SMEs. European Management Journal, 36(1), 59-70. https://doi.org/10.1016/j.emj.2017.03.002

Gunjati, S. B., \& Adake, C. V. (2020). Innovation in Indian SMEs and their current viability: A review. Materials Today: Proceedings, 28, 2325-2330. https://doi.org/10.1016/j.matpr.2020.04.604

Herawati, N. T., Candiasa, I. M., Yadnyana, I. K., \& Suharsono, N. (2020). The influence of gender and financial literacy on accounting implementation in small and micro business (SMES). International Journal of Innovation, Creativity and Change, 12(4), 36-50.

Hossain, M., Yoshino, N., \& Taghizadeh-Hesary, F. (2020). Optimal branching strategy, local financial development, and SMEs' performance. Economic Modelling, March. https://doi.org/10.1016/j.econmod.2020.03.027

Hussain, J., Salia, S., \& Karim, A. (2018). Is knowledge that powerful? Financial literacy and access to finance: An analysis of enterprises in the UK. Journal of Small Business and Enterprise Development, 25(6), 985-1003. https://doi.org/10.1108/JSBED-01-20180021

Knight, G., Moen, Ø., \& Koed, T. (2020). Antecedents to di ff erentiation strategy in the exporting SME. June. https://doi.org/10.1016/j.ibusrev.2020.101740

Kottika, E., Özsomer, A., Rydén, P., Theodorakis, I. G., Kaminakis, K., Kottikas, K. G., \& Stathakopoulos, V. (2020). We survived this! What managers could learn from SMEs who successfully navigated the Greek economic crisis. Industrial Marketing Management, 88(June), 352-365. https://doi.org/10.1016/j.indmarman.2020.05.021

Kurniasih, D., Setyoko, P. I., Imron, M., \& Wijaya, S. S. (2019). The role of stakeholders in the Accountability of Village Enterprise Management: A Public Governance Approach. IOP Conference Series: Earth and Environmental Science, 255(1). https://doi.org/10.1088/1755-1315/255/1/012056

Lambregts, T. R., \& Schut, F. T. (2020). Displaced, disliked and misunderstood: A systematic review of the reasons for low uptake of long-term care insurance and life annuities. Journal of the Economics of Ageing, 17(January), 100236. https://doi.org/10.1016/j.jeoa.2020.100236

Liu, R., \& Wong, T. C. (2018). Urban village redevelopment in Beijing: The state-dominated formalization of informal housing. Cities, 72(February 2017), 160-172. https://doi.org/10.1016/j.cities.2017.08.008

Lorentz, H., Hilmola, O. P., Malmsten, J., \& Srai, J. S. (2016). Cluster analysis application for understanding SME manufacturing strategies. Expert Systems with Applications, 66, 176-188. https://doi.org/10.1016/j.eswa.2016.09.016

Lu, J., Ren, L., Zhang, C., Rong, D., Ahmed, R. R., \& Streimikis, J. (2020). Modified Carroll's pyramid of corporate social responsibility to enhance organizational performance of SMEs industry. Journal of Cleaner Production, 271, 122456. https://doi.org/10.1016/j.jclepro.2020.122456 
Ma'ruf, A. (2019). The improvement strategies for Sharia financial literacy on creative economy. International Journal of Scientific and Technology Research, 8(11), 249-253.

Mabula, J. B., \& Ping, H. D. (2018a). Financial literacy of SME managers' on access to finance and performance: The mediating role of financial service utilization. International Journal of Advanced Computer Science and Applications, 9(9), 32-41. https://doi.org/10.14569/ijacsa.2018.090905

Mabula, J. B., \& Ping, H. D. (2018b). Use of technology and SME managers' financial literacy in developing economies. ACM International Conference Proceeding Series, 9(6), 145152. https://doi.org/10.1145/3241748.3241765

Müller, J. M., Buliga, O., \& Voigt, K. I. (2020). The role of absorptive capacity and innovation strategy in the design of industry 4.0 business Models-A comparison between SMEs and large enterprises. European Management Journal, $x x x x, 1-11$. https://doi.org/10.1016/j.emj.2020.01.002

Nisar, S., Boateng, A., \& Wu, J. (2018). The entry mode strategy and performance of SMEs: Evidence from Norway. Research in International Business and Finance, 45(July 2017), 323-333. https://doi.org/10.1016/j.ribaf.2017.07.164

Nohong, M., Ali, M., Sohilauw, M., Sobarsyah, M., \& Munir, A. (2019). Financial literacy and competitive advantage: SME strategy in reducing business risk. Espacios, 40(32).

Novi Yushita Amanita. (2017). Pentingnya Literasi Keuangan Bagi Pengelolaan Keuangan Pribadi. Jurnal Nominal, VI, 15.

Omri, N., Al Masry, Z., Mairot, N., Giampiccolo, S., \& Zerhouni, N. (2020). Industrial data management strategy towards an SME-oriented PHM. Journal of Manufacturing Systems, 56(April), 23-36. https://doi.org/10.1016/j.jmsy.2020.04.002

Owusu, J., Ismail, M. Bin, Osman, M. H. B. M., \& Kuan, G. (2019). Financial literacy as a moderator linking financial resource availability and SME growth in Ghana. Investment Management and Financial Innovations, 16(1), 154-166. https://doi.org/10.21511/imfi.16(1).2019.12

Paul, J. (2020). SCOPE framework for SMEs: A new theoretical lens for success and internationalization. European Management Journal, 38(2), 219-230. https://doi.org/10.1016/j.emj.2020.02.001

Ruan, J., \& Zhang, X. (2014). "Flying geese" in China: The textile and apparel industry's pattern of migration. Journal of Asian Economics, 34, 79-91. https://doi.org/10.1016/j.asieco.2014.06.003

Santoro, G., Mazzoleni, A., Quaglia, R., \& Solima, L. (2019). Does age matter? The impact of SMEs age on the relationship between knowledge sourcing strategy and internationalization. Journal of Business Research, May, 1-9. https://doi.org/10.1016/j.jbusres.2019.05.021

Sugiarti, E. N., Diana, N., \& Mawardi, M. C. (2019). Peran Fintech Dalam Meningkatkan Literasi Keuangan Pada Usaha Mikro Kecil Menengah Di Malang. E-Jra, 8(4), 90-104.

U, A., \& Majid AH, A. (2015). Role and Impact of Reward and Accountability on Training Transfer. Business and Economics Journal, 07(01), 1-6. https://doi.org/10.4172/21516219.1000195

van Rijnsoever, F. J., Kempkes, S. N., \& Chappin, M. M. H. (2017). Seduced into collaboration: A resource-based choice experiment to explain make, buy or ally strategies of SMEs. Technological Forecasting and Social Change, 120, 284-297. https://doi.org/10.1016/j.techfore.2017.03.015

Westman, L., McKenzie, J., \& Burch, S. L. (2020). Political participation of businesses: A framework to understand contributions of SMEs to urban sustainability politics. Earth 
System Governance, 3, 100044. https://doi.org/10.1016/j.esg.2020.100044

Whiteley, P., \& Kölln, A. K. (2018). How do different sources of partisanship influence government accountability in Europe? International Political Science Review. https://doi.org/10.1177/0192512118780445

Widayanti, R., Damayanti, R., \& Marwanti, F. (2017). Pengaruh Financial Literacy Terhadap Keberlangsungan Usaha (Business Sustainability) Pada Umkm Desa Jatisari. Jurnal IImiah Manajemen \& Bisnis, 18(2), 153. https://doi.org/10.30596/jimb.v18i2.1399

Widyatama, A., \& Yanida, M. (2016). Akuntabilitas Keuangan UMKM: Bagaimana Perspektif dari Sebuah UMKM Bidang Perdagangan? Journal of Research and Applications: Accounting and Management, 1(3), 202. https://doi.org/10.18382/jraam.v1i3.47

Wiemer, C. (1994). State policy and rural resource allocation in China as seen through a Hebei province township, 1970-1985. World Development, 22(6), 935-947. https://doi.org/10.1016/0305-750X(94)90063-9

Woodard, R. (2020). Waste Management in Small and Medium Enterprises (SMEs): compliance with Duty of Care and implications for the Circular Economy. Journal of Cleaner Production. https://doi.org/10.1016/j.scitotenv.2019.135577

Ye, J., \& Kulathunga, K. M. M. C. B. (2019). How does financial literacy promote sustainability in SMEs? A developing country perspective. Sustainability (Switzerland), 11(10), 1-21. https://doi.org/10.3390/su11102990

Zhang, J. (2019). The geographic political economy of art district formation in China: The case of Songzhuang. Geoforum, 106(February 2017), 340-348. https://doi.org/10.1016/j.geoforum.2017.07.018

Zhao, P., \& Zhang, M. (2018). Informal suburbanization in Beijing: An investigation of informal gated communities on the urban fringe. Habitat International, 77(January), 130-142. https://doi.org/10.1016/j.habitatint.2018.01.006 